\title{
Prevalence of microhematuria in renal colic and urolithiasis: a systematic review and meta-analysis
}

\author{
Bruno Minotti ${ }^{1 *}$ D , Giorgio Treglia ${ }^{2}$, Mariarosa Pascale ${ }^{3}$, Samuele Ceruti ${ }^{4}$, Laura Cantini ${ }^{5}$, Luciano Anselmi ${ }^{5}$ and
} Andrea Saporito ${ }^{5}$

\begin{abstract}
Background: This systematic review and meta-analysis aims to investigate the prevalence of microhematuria in patients presenting with suspected acute renal colic and/or confirmed urolithiasis at the emergency department.

Methods: A comprehensive literature search was conducted to find relevant data on prevalence of microhematuria in patients with suspected acute renal colic and/or confirmed urolithiasis. Data from each study regarding study design, patient characteristics and prevalence of microhematuria were retrieved. A random effect-model was used for the pooled analyses.

Results: Forty-nine articles including 15'860 patients were selected through the literature search. The pooled microhematuria prevalence was $77 \%(95 \% \mathrm{Cl}: 73-80 \%)$ and $84 \%$ (95\% $\mathrm{Cl}: 80-87 \%)$ for suspected acute renal colic and confirmed urolithiasis, respectively. This proportion was much higher when the dipstick was used as diagnostic test (80 and 90\% for acute renal colic and urolithiasis, respectively) compared to the microscopic urinalysis (74 and 78\% for acute renal colic and urolithiasis, respectively).

Conclusions: This meta-analysis revealed a high prevalence of microhematuria in patients with acute renal colic (77\%), including those with confirmed urolithiasis (84\%). Intending this prevalence as sensitivity, we reached moderate values, which make microhematuria alone a poor diagnostic test for acute renal colic or urolithiasis. Microhematuria could possibly still important to assess the risk in patients with renal colic.
\end{abstract}

Keywords: Renal colic, Urolithiasis, Microhematuria, Stone score

\section{Background}

Renal colic is caused by the presence of stones in the urinary tract and it is characterized by sudden onset of severe loin pain, radiating to the flank, groin, and testes or labia majora [1]. Incidence amounts to 240 per 100' 000 persons [2] with a prevalence up to $10 \%$; men are commonly more affected than women with a ratio of 3-

\footnotetext{
* Correspondence: bruno.minotti@kssg.ch

'Emergency Department, Cantonal Hospital of St. Gallen, Rorschacher Strasse 95, CH-9007 St. Gallen, Switzerland

Full list of author information is available at the end of the article
}

2:1 [3]. Lifetime risk is up to $19 \%$ in men and $9 \%$ in women [4], varying depending on geographic location and increasing constantly over last years [5]. Guidelines for the diagnostic pathway suggest assessing (micro) hematuria, while the gold standard of imaging is unenhanced multi-detector computed tomography (MDCT) [1]. As diagnostic tool the STONE Score was developed and validated; this score includes parameters as sex, duration of pain prior to presentation, race, nausea, vomiting and microhematuria [6]. Microhematuria prevalence in suspected renal colic has been studied in several trials, ranging from $55 \%[7]$ to $93 \%[8,9]$. In order to better

(c) The Author(s). 2020 Open Access This article is licensed under a Creative Commons Attribution 4.0 International License, which permits use, sharing, adaptation, distribution and reproduction in any medium or format, as long as you give appropriate credit to the original author(s) and the source, provide a link to the Creative Commons licence, and indicate if changes were made. The images or other third party material in this article are included in the article's Creative Commons licence, unless indicated otherwise in a credit line to the material. If material is not included in the article's Creative Commons licence and your intended use is not permitted by statutory regulation or exceeds the permitted use, you will need to obtain permission directly from the copyright holder. To view a copy of this licence, visit http://creativecommons.org/licenses/by/4.0/. The Creative Commons Public Domain Dedication waiver (http://creativecommons.org/publicdomain/zero/1.0/) applies to the data made available in this article, unless otherwise stated in a credit line to the data. 
understand the difference existing in prevalence range, we performed a meta-analysis of studies dealing with microhematuria by suspected acute renal colic and/or confirmed urolithiasis.

\section{Methods}

This systematic review and meta-analysis conforms to the statement on Preferred Reporting Items for Systematic reviews and Meta-Analyses [10].

\section{Search strategy}

A literature search of the electronic PubMed/MEDLINE database and Cochrane Central Register of Controlled Trials (CENTRAL), without language restriction, was carried out from inception to October 11, 2018. A search algorithm was established using a combination of the following terms: A) renal colic AND urolithiasis (Problem), B) urinalysis (Intervention), C) microhematuria (Outcome). The final search query is reported in Appendix 1. Reference lists of the retrieved articles were also screened for additional studies.

\section{Eligibility criteria}

We included in this systematic review and meta-analysis studies which filled the following inclusion criteria: a) original article published in peer-reviewed journal; b) studies including adults only; c) patients presenting with acute renal colic at the emergency department; d) studies reporting data on microhematuria.

Exclusion criteria were: a) articles not within the field of interest of this review; b) review articles, letters or editorials; c) case reports or case series (less than 10 patients included); d) articles with possible patient data overlap.

\section{Study selection}

Titles and abstracts of the retrieved studies were independently reviewed by two researchers (MP, GT), applying the inclusion and exclusion criteria mentioned above. Articles were rejected if they were clearly ineligible. The full texts of the potentially eligible articles were reviewed independently by the same researchers to confirm or exclude their eligibility for inclusion. Disagreements were resolved in a consensus meeting.

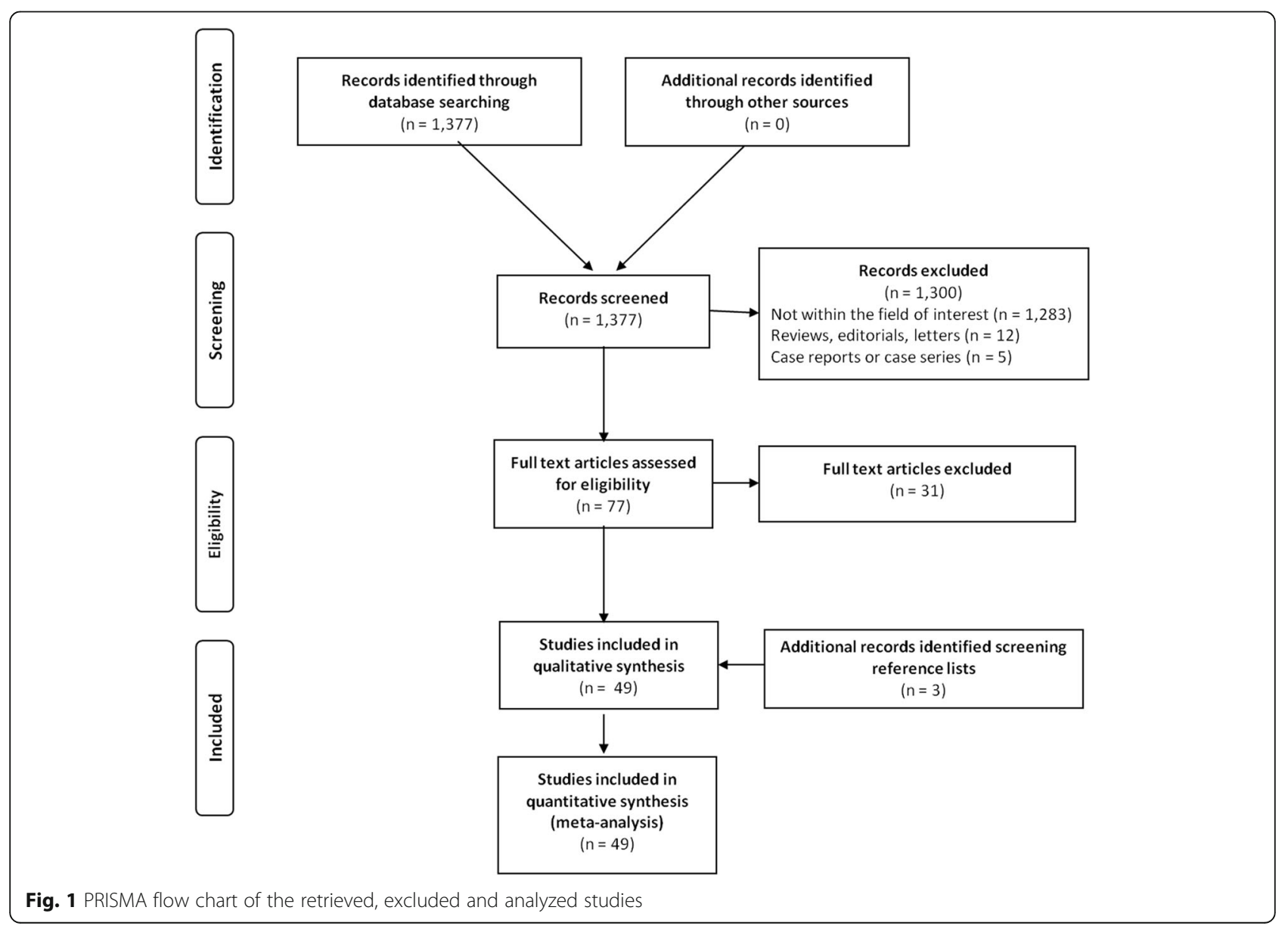


Table 1 Basic study and patient characteristics. Patients presenting with acute renal colic at the emergency department

\begin{tabular}{|c|c|c|c|c|c|c|}
\hline Authors & Year & Country & Study design & No. of patients & $\%$ Male & Mean age $\pm S D$ (years) \\
\hline Kim et al. [13] & 2018 & South Korea & Retrospective, observational & 798 & 68.6 & $48.2 \pm 13.3$ \\
\hline Desai et al. [14] & 2018 & USA & Retrospective, observational & 350 & NR & NR \\
\hline Türk and Ün [15] $]^{\mathrm{a}}$ & 2017 & Turkey & Prospective, observational & 516 & 60.5 & $37 \pm 20.3$ \\
\hline Shrestha et al. [16] ${ }^{\mathrm{a}}$ & 2017 & Nepal & Retrospective, observational & 201 & 55.2 & $29 \pm 13.5$ \\
\hline Odoemene et al. [17] $]^{\mathrm{a}}$ & 2017 & Nigeria & Prospective, observational & 69 & 76.8 & $40.4 \pm 2.9$ \\
\hline Mefford et al. [18] & 2017 & USA & Retrospective, observational & 393 & 69 & Median 43 (IQR 32-54) \\
\hline Rapp et al. [19] & 2016 & USA & Retrospective, observational & 613 & 47 & $49 \pm 0.6$ \\
\hline Park et al. [20] & 2016 & $\begin{array}{l}\text { South } \\
\text { Korea }\end{array}$ & Prospective, RCT & 103 & 66 & $45.6 \pm 12.55$ \\
\hline Hernandez et al. [21] & 2016 & USA & Retrospective, observational & 536 & 56 & $45.9 \pm 16.3$ \\
\hline Fukuhara et al. [22] ${ }^{a}$ & 2016 & Japan & Retrospective, observational & 491 & 70.5 & $51.8 \pm 15$ \\
\hline Dorfman et al. [23] & 2016 & USA & Retrospective, observational & 339 & 55.5 & $46.8 \pm 16.5$ \\
\hline Yan et al. [24] & 2015 & Canada & Prospective cohort study & 565 & 62.8 & $46.6 \pm 14.4$ \\
\hline Lee et al. [25] & 2015 & $\begin{array}{l}\text { South } \\
\text { Korea }\end{array}$ & Retrospective, observational & 2218 & 71 & $43.3 \pm 14.2$ \\
\hline Hall et al. [26] ${ }^{\mathrm{a}}$ & 2015 & UK & Retrospective, observational & 513 & 57.1 & $45 \pm 23.3$ \\
\hline Zwank et al. [27] & 2014 & USA & Prospective, observational & 93 & NR & $39 \pm N R$ \\
\hline Abdel-Gawad et al. [28] ${ }^{\mathrm{a}}$ & 2014 & UAE & Retrospective, observational & 939 & 87.9 & $37.9 \pm 11$ \\
\hline Inci et al. [7] & 2013 & Turkey & Retrospective, observational & 83 & 42.2 & $42.1 \pm 14.4$ \\
\hline Lallas et al. [29] & 2011 & USA & Prospective, observational & 32 & NR & NR \\
\hline Perez et al. [30] ${ }^{\mathrm{a}}$ & 2010 & Spain & Prospective, multicentre, cross-sectional case-control & 146 & 57.53 & $51.34 \pm N R$ \\
\hline Xafis et al. [31] ${ }^{\mathrm{a}}$ & 2008 & Switzerland & Retrospective, observational & 638 & NR & $44.3 \pm 14.6$ \\
\hline Serinken et al. [32] ${ }^{\mathrm{a}}$ & 2008 & Turkey & Retrospective, observational & 235 & 75.7 & $31.1 \pm 7$ \\
\hline Cupisti et al. [33] & 2008 & Italy & Retrospective, observational & 696 & 54 & NR \\
\hline Matani and Al-Ghazo [34] ${ }^{\mathrm{a}}$ & 2007 & Saudi Arabia / Jordan & Retrospective, observational & 75 & 61.3 & $42.2 \pm N R$ \\
\hline Kartal et al. [35] ${ }^{\mathrm{a}}$ & 2006 & Turkey & Prospective, observational & 227 & 64.8 & $38.4 \pm 14$ \\
\hline Kirpalani et al. [36] & 2005 & Canada & Retrospective, observational & 299 & NR & NR \\
\hline Gaspari and Horst [37] & 2005 & USA & Prospective, observational & 110 & NR & NR \\
\hline Argyropoulos et al. [8] & 2004 & Greece & Retrospective, observational & 609 & 63.2 & $49.2 \pm 15.9$ \\
\hline Unal et al. [38] ${ }^{\mathrm{a}}$ & 2003 & Turkey & Prospective, observational & 137 & 55 & $38 \pm N R$ \\
\hline Tack et al. [39] $]^{\mathrm{a}}$ & 2003 & Belgium & Prospective, observational & 106 & 50 & $45 \pm N R$ \\
\hline Kobayashi et al. [40] & 2003 & Japan & Retrospective, observational & 537 & 78 & $46.6 \pm 14$ \\
\hline Eray et al. [41] & 2003 & Turkey & Prospective, observational & 65 & 60 & $38.8 \pm 13.5$ \\
\hline Lucks et al. [42] & 2002 & USA & Retrospective, observational & 587 & NR & NR \\
\hline Hamm et al. [43] & 2002 & Germany & Prospective, observational & 109 & 69.7 & $49 \pm N R$ \\
\hline Li et al. [44] $]^{a}$ & 2001 & USA & Retrospective, observational & 397 & 73 & $47 \pm 15$ \\
\hline Hamm et al. [45] & 2001 & Germany & Prospective, observational & 125 & 72 & $55 \pm 17$ \\
\hline Richards and Christman [46] & 1999 & USA & Retrospective, observational & 185 & NR & NR \\
\hline Bove et al. [47] & 1999 & USA & Retrospective, observational & 195 & NR & NR \\
\hline Ooi et al. [9] $]^{\mathrm{a}}$ & 1998 & Singapore & Prospective, observational & 122 & 93 & $39.7 \pm N R$ \\
\hline Ghali et al. [48] $]^{\mathrm{a}}$ & 1998 & Saudi Arabia & Prospective, observational & 125 & 80 & $39.2 \pm N R$ \\
\hline Eskelinen et al. [49] & 1998 & Finland & Prospective, observational & 57 & NR & NR \\
\hline Gimondo et al. [50] ${ }^{\mathrm{a}}$ & 1996 & Italy & Retrospective, observational & 76 & 60.5 & $47 \pm N R$ \\
\hline Boyd and Gray [51] & 1996 & UK & Prospective, observational & 52 & NR & NR \\
\hline Press and Smith [52] & 1995 & USA & Retrospective, observational & 109 & NR & NR \\
\hline Chia et al. [53] & 1995 & Singapore & Prospective, observational & 294 & 72.5 & $43.5 \pm N R$ \\
\hline Elton et al. [54] ${ }^{\mathrm{a}}$ & 1993 & USA & Retrospective / prospective, observational & 275 & 71.2 & $46.2 \pm 15.7$ \\
\hline Stewart et al. [55] & 1990 & USA & Retrospective, observational & 160 & 76.9 & NR \\
\hline
\end{tabular}


Table 1 Basic study and patient characteristics. Patients presenting with acute renal colic at the emergency department (Continued)

\begin{tabular}{|c|c|c|c|c|c|c|}
\hline Authors & Year & Country & Study design & No. of patients & $\%$ Male & Mean age \pm SD (years) \\
\hline Freeland [56] & 1987 & Northern Ireland & Retrospective, observational & 134 & NR & NR \\
\hline Dunn et al. [57] & 1985 & USA & Retrospective, observational & 76 & NR & $42.7 \pm N R$ \\
\hline Bishop [58] & 1980 & UK & Prospective, observational & 50 & NR & NR \\
\hline
\end{tabular}

Abbreviations (alphabetical order): IQR interquartile range, NR not reported, RCT Randomized controlled study, SD standard deviation, UAE United Arab Emirates, UK United Kingdom, USA United States of America

${ }^{\mathrm{a}}$ Enrolled also children

\section{Data extraction}

For each included study, one author (MP) manually extracted data relevant to the review aims using a customized form. Information regarding basic study data (authors, year of publication, country of origin, type of study), patient characteristics (number of patients, mean age, gender), methods (microhematuria test, microhematuria definition) and outcomes (number of patients with microhematuria, microhematuria prevalence) were retrieved. The number of patients with microhematuria and microhematuria prevalence were also extracted for patients with confirmed urolithiasis, where available. Diagnostic methods for detection of stones were also retrieved. One other author (GT) independently checked all extracted data.

\section{Outcome measures}

The primary outcome was the percentage of microhematuria among patients presenting with suspected acute renal colic at the emergency department. The secondary outcome was the percentage of microhematuria among patients presenting with acute renal colic and confirmed urolithiasis at the emergency department.

\section{Quality assessment}

The overall quality of the studies included in the systematic review was critically appraised based on the revised "Quality Assessment of Diagnostic Accuracy Studies" tool (QUADAS-2). This tool comprises four domains: patient selection, index test, reference standard, and flow and timing. Each domain was assessed in terms of risk of bias, and the first three domains were also assessed in terms of concerns regarding applicability. Two authors have performed the risk of bias assessment (GT and $\mathrm{MP}$ ) reaching a consensus.

\section{Statistical analysis}

Microhematuria prevalence was defined as the ratio between the number of patients with suspected acute renal colic with microhematuria detected by urinalysis or dipstick and the total number of patients with suspected acute renal colic who underwent the analysis. This proportion was calculated also for patients presenting with acute renal colic and confirmed urolithiasis.
Pooled analyses of the proportion of microhematuria detected by urinalysis or dipstick were performed using data retrieved from the selected studies. When microhematuria was assessed using both urinalysis and dipstick, the test with the better outcome was chosen. Subgroup analyses taking into account the microhematuria test were planned.

A random-effects model was used for statistical pooling of the data, taking into account the heterogeneity between studies. The different weight of each study in the pooled analysis was related to the different sample size. Pooled data were presented with their respective 95\% confidence interval $(95 \% \mathrm{CI})$ values, and data were displayed using plots.

Heterogeneity was estimated by using the I-square index $\left(\mathrm{I}^{2}\right)$, which describes the percentage of variation across studies that is due to heterogeneity rather than chance [11] and considered significant if I-square test was higher than $50 \%$.

Publication bias was assessed through the Egger's test [12].

Statistical analyses were performed using the StatsDirect software version 3 (StatsDirect Ltd., Cambridge, UK).

\section{Results}

Literature search

The literature search from PubMed/MEDLINE and Cochrane CENTRAL databases yielded a total of 1377 records. After reviewing titles and abstracts, 77 were selected as potentially eligible articles. The full text was retrieved for all. Following eligibility's assessment, 31 articles did not meet the inclusion criteria and were excluded from the systematic review. Within the selected articles, screening of the reference lists allowed to add 3 additional records. Finally, 49 studies [7-9, 13-58] including 15' 860 patients were identified as potentially relevant and were selected for the systematic review and meta-analysis. All of the included studies except two $[30,50]$ were published in English. These studies covered the period from inception to October 11, 2018. Search results and articles' selection are displayed in a PRISMA flow chart (Fig. 1).

\section{Selected studies}

The characteristics of selected studies are reported in Table 1. The studies were conducted in different 
Table 2 Data on microhematuria in patients presenting with suspected acute renal colic at the emergency department

\begin{tabular}{|c|c|c|c|c|c|}
\hline Authors & $\begin{array}{l}\text { Microhematuria } \\
\text { test }\end{array}$ & $\begin{array}{l}\text { Type of } \\
\text { hematuria }\end{array}$ & Positive microhematuria definition & $\begin{array}{l}\text { No. patients with } \\
\text { microhematuria }\end{array}$ & $\begin{array}{l}\text { Microhematuria } \\
\text { prevalence }\end{array}$ \\
\hline Kim et al. [13] & Urinalysis & Microscopic & Presence of 4 or more RBCs/HPF & 750 & $750 / 798(94 \%)$ \\
\hline Desai et al. [14] & Urinalysis & $\begin{array}{l}\text { Microscopic or } \\
\text { macroscopic }\end{array}$ & Positive urinalysis for RBCs or for blood & 245 & 245/350 (70\%) \\
\hline Türk and Ün [15] & Urinalysis & Microscopic & NR & 432 & $432 / 516(83.7 \%)$ \\
\hline $\begin{array}{l}\text { Shrestha et al. } \\
{[16]}\end{array}$ & Urinalysis & Microscopic & Presence of 3 or more RBCs & 70 & $70 / 201(34.8 \%)$ \\
\hline $\begin{array}{l}\text { Odoemene et al. } \\
{[17]}\end{array}$ & Urinalysis & $\begin{array}{l}\text { Microscopic or } \\
\text { macroscopic }\end{array}$ & NR & 62 & $62 / 69(89.9 \%)$ \\
\hline $\begin{array}{l}\text { Mefford et al. } \\
{[18]}\end{array}$ & Urinalysis & Microscopic & Presence of 4 or more RBCs/HPF & 321 & $321 / 393(81.7 \%)$ \\
\hline Rapp et al. [19] & Urinalysis & $\begin{array}{l}\text { Microscopic or } \\
\text { macroscopic }\end{array}$ & Presence of 4 or more RBCs/HPF & 412 & $412 / 613(67.2 \%)$ \\
\hline Park et al. [20] & Urinalysis & Microscopic & NR & 90 & $90 / 103(87.4 \%)$ \\
\hline $\begin{array}{l}\text { Hernandez et al. } \\
\text { [21] }\end{array}$ & Urine dipstick & Microscopic & Hematuria on urine dipstick & 332 & $332 / 536(61.9 \%)$ \\
\hline $\begin{array}{l}\text { Fukuhara et al. } \\
\text { [22] }\end{array}$ & $\begin{array}{l}\text { Urinalysis or } \\
\text { urine dipstick }\end{array}$ & $\begin{array}{l}\text { Microscopic or } \\
\text { macroscopic }\end{array}$ & Occult blood in urine & 352 & $352 / 491(71.7 \%)$ \\
\hline $\begin{array}{l}\text { Dorfman et al. } \\
\text { [23] }\end{array}$ & Urinalysis & Microscopic & Presence of 5 or more RBCs/HPF & 254 & $254 / 339$ (74.9\%) \\
\hline Yan et al. [24] & Urinalysis & Microscopic & NR & 451 & $451 / 565(79.8 \%)$ \\
\hline Lee et al. [25] & Urinalysis & Microscopic & NR & 1980 & $\begin{array}{l}1980 / 2218 \\
(89.3 \%)\end{array}$ \\
\hline Hall et al. [26] & Urine dipstick & $\begin{array}{l}\text { Microscopic or } \\
\text { macroscopic }\end{array}$ & $\begin{array}{l}\text { Scores of } 1+\text { to } 3+\text { on urine dipstick or } \\
\text { documented frank hematuria }\end{array}$ & 391 & $391 / 513(76.2 \%)$ \\
\hline Zwank et al. [27] & Urinalysis & Microscopic & RBCs present & 66 & $66 / 93(71 \%)$ \\
\hline $\begin{array}{l}\text { Abdel-Gawad } \\
\text { et al. [28] }\end{array}$ & Urinalysis & Microscopic & Presence of 4 or more RBCs/HPF & 835 & 835/939 (88.9\%) \\
\hline Inci et al. [7] & Urinalysis & Microscopic & Presence of 5 or more RBCs/HPF & 46 & 46/83 (55.4\%) \\
\hline \multirow[t]{2}{*}{ Lallas et al. [29] } & Urinalysis & Microscopic & Presence of 4 or more RBCs/HPF & 18 & 18/32 (56.3\%) \\
\hline & Urine dipstick & Microscopic & Trace or scores of $1+$ to $4+$ on urine dipstick & 21 & $21 / 32(65.6 \%)$ \\
\hline Perez et al. [30] & Urine dipstick & Microscopic & NR & 132 & $132 / 146(90.4 \%)$ \\
\hline Xafis et al. [31] & Urinalysis & Microscopic & Presence of 5 or more RBCs/HPF & 396 & $396 / 638(62.1 \%)$ \\
\hline $\begin{array}{l}\text { Serinken et al. } \\
\text { [32] }\end{array}$ & Urinalysis & Microscopic & Presence of 5 or more RBCs/HPF & 194 & 194/235 (82.6\%) \\
\hline Cupisti et al. [33] & Urine dipstick & Microscopic & NR & 592 & $592 / 696(85.1 \%)$ \\
\hline $\begin{array}{l}\text { Matani and Al- } \\
\text { Ghazo [34] }\end{array}$ & Urinalysis & Microscopic & Presence of 4 or more RBCs/HPF & 50 & $50 / 75(66.7 \%)$ \\
\hline Kartal et al. [35] & Urinalysis & Microscopic & Presence of 10 or more RBCs/HPF & 146 & $146 / 227(64.3 \%)$ \\
\hline $\begin{array}{l}\text { Kirpalani et al. } \\
\text { [36] }\end{array}$ & Urine dipstick & Microscopic & Positive urine dipstick & 228 & $228 / 299(76.3 \%)$ \\
\hline $\begin{array}{l}\text { Gaspari and } \\
\text { Horst [37] }\end{array}$ & Urinalysis & Microscopic & Presence of 5 or more RBCs/HPF & 82 & $82 / 110(74.5 \%)$ \\
\hline $\begin{array}{l}\text { Argyropoulos } \\
\text { et al. [8] }\end{array}$ & Urine dipstick & Microscopic & Scores of $1+$ to $3+$ on urine dipstick & 566 & $566 / 609$ (92.9\%) \\
\hline Unal et al. [38] & Urinalysis & Microscopic & Presence of 4 or more RBCs/HPF & 100 & 100/137 (73\%) \\
\hline Tack et al. [39] & $\begin{array}{l}\text { Urinalysis or } \\
\text { Urine dipstick }\end{array}$ & Microscopic & Presence of 2 or more RBCs/HPF or positive dipstick & 77 & 77/106 (72.6\%) \\
\hline \multirow{2}{*}{$\begin{array}{l}\text { Kobayashi et al. } \\
\text { [40] }\end{array}$} & Urine dipstick & Microscopic & Scores of $1+$ to $3+$ on urine dipstick & 382 & $382 / 537(71.1 \%)$ \\
\hline & Urinalysis & Microscopic & Presence of 5 or more RBCs/HPF & 350 & $350 / 537(65.2 \%)$ \\
\hline
\end{tabular}


Table 2 Data on microhematuria in patients presenting with suspected acute renal colic at the emergency department (Continued)

\begin{tabular}{|c|c|c|c|c|c|}
\hline Authors & $\begin{array}{l}\text { Microhematuria } \\
\text { test }\end{array}$ & $\begin{array}{l}\text { Type of } \\
\text { hematuria }\end{array}$ & Positive microhematuria definition & $\begin{array}{l}\text { No. patients with } \\
\text { microhematuria }\end{array}$ & $\begin{array}{l}\text { Microhematuria } \\
\text { prevalence }\end{array}$ \\
\hline Eray et al. [41] & Urinalysis & Microscopic & Presence of 6 or more RBCs/HPF & 45 & $45 / 20(69.2 \%)$ \\
\hline Luchs et al. [42] & Urinalysis & Microscopic & Presence of 10 or more RBCs/HPF & 492 & $492 / 587(83.8 \%)$ \\
\hline Hamm et al. [45] & Urinalysis & Microscopic & Presence of more than $20 \mathrm{mg} / \mathrm{dl}$ hemoglobin & 66 & $66 / 109(60.6 \%)$ \\
\hline Li et al. [44] & $\begin{array}{l}\text { Urinalysis or } \\
\text { Urine dipstick }\end{array}$ & Microscopic & $\begin{array}{l}\text { Presence of any number of RBCs/HPF or trace / } \\
\text { scores of } 1+\text { to } 3+\text { on urine dipstick }\end{array}$ & 360 & $360 / 397(90.7 \%)$ \\
\hline Hamm et al. [45] & Urinalysis & Microscopic & Presence of 4 or more RBCs/HPF & 99 & $99 / 125(79.2 \%)$ \\
\hline $\begin{array}{l}\text { Richards and } \\
\text { Christman [46] }\end{array}$ & Urinalysis & Microscopic & Presence of 4 or more RBCs/HPF & 156 & $156 / 185(84.3 \%)$ \\
\hline \multirow[t]{3}{*}{ Bove et al. [47] } & Urine dipstick & Microscopic & Positive urine dipstick & 130 & 130/180 (72.2\%) \\
\hline & Urinalysis & Microscopic & Presence of 6 or more RBCs/HPF & 128 & $128 / 195(65.6 \%)$ \\
\hline & $\begin{array}{l}\text { Urinalysis or } \\
\text { Urine dipstick }\end{array}$ & Microscopic & $\begin{array}{l}\text { Presence of } 2 \text { or more RBCs/HPF or positive urine } \\
\text { dipstick }\end{array}$ & 153 & 153/195 (78.5\%) \\
\hline \multirow[t]{2}{*}{ Ooi et al. [9] } & Urine dipstick & Microscopic & Scores of $1+$ or more on urine dipstick & 114 & 114/122 (93.4\%) \\
\hline & Urinalysis & Microscopic & $\begin{array}{l}\text { Presence of } 6 \text { or more RBCs/HPF in males or of } 10 \\
\text { or more RBCs/HPF in females }\end{array}$ & 77 & $77 / 122(63.1 \%)$ \\
\hline Ghali et al. [48] & Urinalysis & Microscopic & Presence of 4 or more RBCs/HPF & 81 & $81 / 125(64.8 \%)$ \\
\hline $\begin{array}{l}\text { Eskelinen et al. } \\
\text { [49] }\end{array}$ & Urinalysis & Microscopic & Presence of 11 or more RBCs/HPF & 43 & 43/57 (75.4\%) \\
\hline $\begin{array}{l}\text { Gimondo et al. } \\
\text { [50] }\end{array}$ & Urine dipstick & $\begin{array}{l}\text { Microscopic or } \\
\text { macroscopic }\end{array}$ & Positive urine dipstick & 56 & 56/76 (73.7\%) \\
\hline $\begin{array}{l}\text { Boyd and Gray } \\
\text { [51] }\end{array}$ & Urine dipstick & Microscopic & Positive urine dipstick & 45 & $45 / 52(86.5 \%)$ \\
\hline $\begin{array}{l}\text { Press and Smith } \\
\text { [52] }\end{array}$ & Urinalysis & Microscopic & Presence of 1 or more RBCs/HPF & 78 & 78/109 (71.6\%) \\
\hline Chia et al. [53] & Urinalysis & Microscopic & $\begin{array}{l}\text { Presence of } 6 \text { or more RBCs/HPF in males or of } 10 \\
\text { or more RBCs/HPF in females }\end{array}$ & 181 & $181 / 294(61.6 \%)$ \\
\hline Elton et al. [54] & Urinalysis & Microscopic & Presence of 4 or more RBCs/HPF & 194 & $194 / 275(70.5 \%)$ \\
\hline Stewart et al. [55] & Urinalysis & Microscopic & Presence of 3 or more RBCs/HPF & 132 & $132 / 160(82.5 \%)$ \\
\hline Freeland [56] & Urine dipstick & Microscopic & Trace or scores of $1+$ to $3+$ on urine dipstick & 102 & 102/134 (76.1\%) \\
\hline Dunn et al. [57] & Urinalysis & Microscopic & Presence of 3 or more RBCs/HPF & 62 & $62 / 76(81.6 \%)$ \\
\hline Bishop [58] & Urine dipstick & Microscopic & Positive urine dipstick & 44 & $44 / 50(88 \%)$ \\
\hline
\end{tabular}

Abbreviations (alphabetical order): NR not reported, HPF High power Field, RBC Red Blood Cell

countries worldwide (Europe, North America, Asia, Africa). The sample size of the included trials ranged from 32 to 2218 adults presenting to the emergency department or urology clinic with acute renal colic. Most of the studies were observational with a prospective (19) or retrospective (29) or mixed (1) design.

Microhematuria was tested by urinalysis in 32 studies, urine dipstick in 10 and both methods in 7. Definition of microhematuria was different among the included studies. Six studies included also patients presenting with macroscopic hematuria $[14,17,19,22,26,50]$. Details on the microhematuria test are reported in Table 2.

\section{Quality assessment}

Overall quality assessment of the studies included in the systematic review according to QUADAS-2 tool is reported in Supplemental Figure 1.

\section{Microhematuria prevalence and suspected acute renal colic}

Primary outcome characteristics on microhematuria prevalence in patients with suspected acute renal colic are summarized in Table 2 and Fig. 2.

Prevalence of microhematuria ranged from 35 to $94 \%$, with a pooled estimate of $77 \%$ (95\%CI: $73-$ 80\%) (Fig. 2). The heterogeneity among the included studies was significant $\left(\mathrm{I}^{2}=96 \%\right)$. A publication bias was detected by Egger's test $(p<0.0001)$.

Performing sub-group analyses taking into account different microhematuria tests, the pooled prevalence of microhematuria using urinalysis or urine dipstick was 74\% (95\%CI: 69-78\%) and 80\% (95\%CI: 74-86\%) respectively, without significant difference between two groups. 


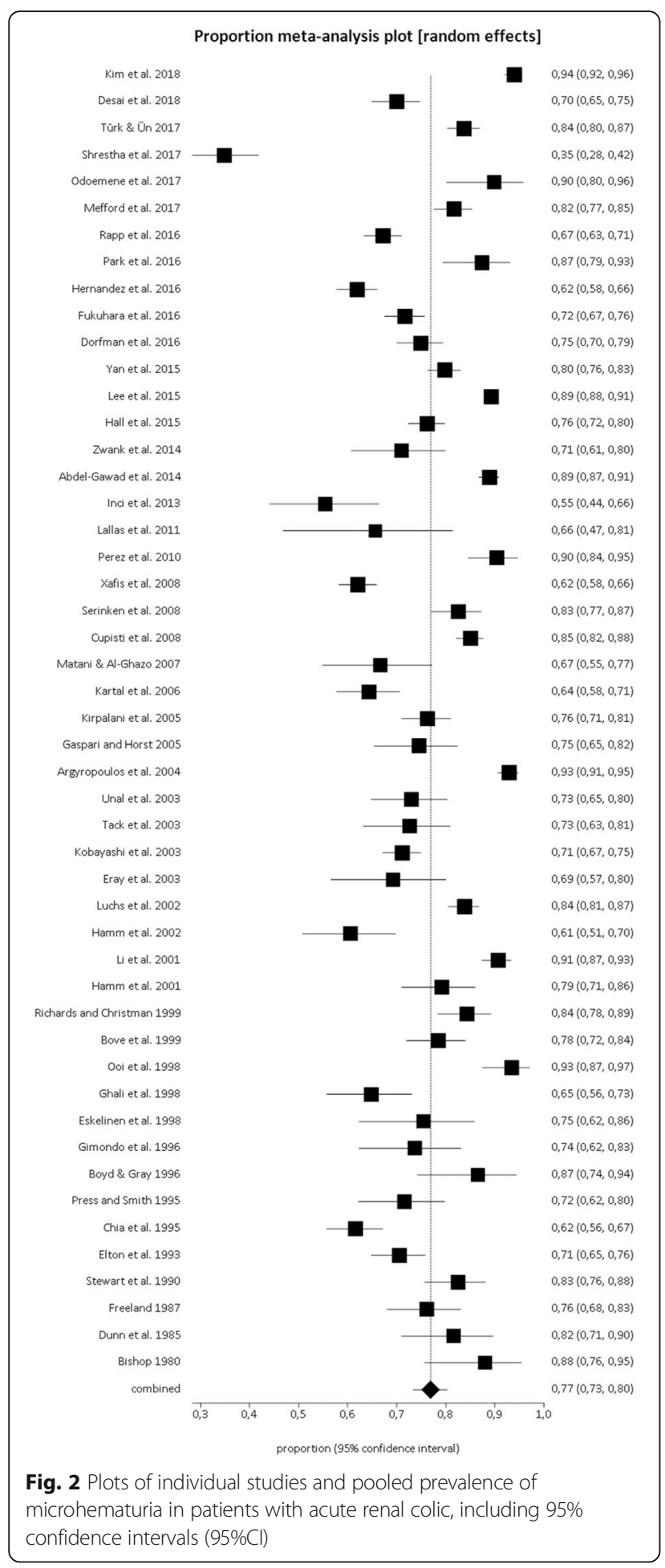

Microhematuria prevalence and confirmed urolithiasis

Secondary outcomes regarding main findings on microhematuria prevalence in patients with acute renal colic and confirmed urolithiasis are summarized in Table 3 and Fig. 3.

Prevalence of microhematuria ranged from 44 to $100 \%$, with a pooled estimate of $84 \%$ (95\%CI: $80-87 \%)$
(Fig. 3). Heterogeneity among the included studies was significant $\left(\mathrm{I}^{2}=93 \%\right)$. A publication bias was detected by Egger's test $(p=0.0008)$.

Performing sub-group analyses taking into account different microhematuria tests, the pooled prevalence of microhematuria using urinalysis or urine dipstick was 78\% (95\%CI: 74-82\%) and 90\% (95\%CI: 83-95\%), respectively.

\section{Discussion}

Many studies have evaluated the prevalence of microhematuria in patients with suspected acute renal colic (Table 1); this meta-analysis pooled data reported in the published studies to derive a more precise assessment. Overall, this systematic review and meta-analysis revealed a high prevalence of microhematuria in patients with acute renal colic (77\%), including those with confirmed urolithiasis $(84 \%)$. However, intending this prevalence as sensitivity, we reached moderate values, which make microhematuria alone a poor diagnostic test for acute renal colic, respectively for urolithiasis. In our meta-analysis heterogeneity was high; indeed, we found a poor definition regarding urine analysis across studies (see positive microhematuria definition in Table 2), with different cells count on microscopy, but also with various dipstick brands. Argyropoulos et al. [8] carried out a microscopic urinalysis when the dipstick was in doubt or with blood traces; microhematuria was confirmed in all of these cases. Thus, the authors concluded that urinary dipstick test is not inferior to microscopy. Bataille et al. [59] compared the sensitivity of urinary dipstick with microscopy and flow cytometry on in vitro contaminated human urine with human blood of volunteers at different concentrations. Urinary dipstick reached the best sensitivity, probably due to the ability to detect red blood cells after lysis, and was suggested as preferred test for screening of hematuria. Same results were previously reported by Kobayashi et al. [40] and Press et al. [52]. De facto we detected a trend toward a higher pooled prevalence of microhematuria by using urine dipstick compared to microscopic urinalysis. Some studies analyzed the characteristics of patients with renal colic and negative microhematuria, the most without correlation between size, location or composition of the stones, or grade of the obstruction [44, 52, 55, 57]. Kobayashi et al. [40] found a relation between hematuria and pain onset, with the highest incidence of negative hematuria on day 3 and 4. Kim et al. [13] found negative microhematuria in patients with lower stones or elevated serum blood urea nitrogen (BUN). Mefford et al. [18] showed an increased prevalence of hydronephrosis in patients with urolithiasis and negative microhematuria. As hydronephrosis is easy to screen with ultrasonography, Daniel et al. [60] developed the STONE PLUS 
Table 3 Data on microhematuria in patients presenting with confirmed urolithiasis at the emergency department

\begin{tabular}{|c|c|c|c|c|}
\hline Authors & Microhematuria test & $\begin{array}{l}\text { No. patients with } \\
\text { microhematuria }\end{array}$ & $\begin{array}{l}\text { Microhematuria } \\
\text { prevalence }\end{array}$ & Diagnostic test for urolithiasis \\
\hline Kim et al. [13] & Urinalysis & 750 & 750/798 (94\%) & Unenhanced MDCT \\
\hline Desai et al. [14] & Urinalysis & 231 & 231/282 (81.9\%) & Non-contrast $C T$ \\
\hline Türk et al. [15] & Urinalysis & 344 & $344 / 388(88.7 \%)$ & Non-contrast complete abdominal CT \\
\hline Shrestha et al. [16] & Urinalysis & 27 & 27/61 (44.3\%) & Renal US \\
\hline Odoemene et al. [17] $]^{a}$ & Urinalysis & 62 & $62 / 69(89.9 \%)$ & Abdominal US, IVU, CT \\
\hline Mefford et al. [18] & Urinalysis & 321 & $321 / 393(81.7 \%)$ & Non-contrast abdominal or pelvic $C T$ \\
\hline Rapp et al. [19] ${ }^{\mathrm{a}}$ & Urinalysis & 177 & 177/222 (79.7\%) & Non-contrast $C T$ \\
\hline Fukuhara et al. [22] ${ }^{\mathrm{a}}$ & $\begin{array}{l}\text { Urinalysis or urine } \\
\text { dipstick }\end{array}$ & 323 & $323 / 358(90.2 \%)$ & $\begin{array}{l}\text { Plain abdominal X-ray, helical contrast enhanced or non- } \\
\text { contrast CT }\end{array}$ \\
\hline Dorfman et al. [23] & Urinalysis & 254 & 245/339 (74.9\%) & Abdominal $C T$ \\
\hline Hall et al. [26] ${ }^{\mathrm{a}}$ & Urine dipstick & 193 & 193/233 (82.8) & Non-enhanced CT \\
\hline Zwank et al. [27] & Urinalysis & 52 & $52 / 62(83.9)$ & $\subset \mathrm{CT}$ \\
\hline Abdel-Gawad et al. [28] & Urinalysis & 835 & 835/939 (88.9) & Color doppler or gray-scale US, abdomen X-ray, helical CT \\
\hline Inci et al. [7] & Urinalysis & 46 & $46 / 83(55.4)$ & Unenhanced MDCT \\
\hline \multirow[t]{2}{*}{ Lallas et al. [29] } & Urinalysis & 18 & 18/32 (56.3) & US, Abdomen X-ray, IVU, $\subset T$ \\
\hline & Urine dipstick & 21 & $21 / 32(65.6)$ & \\
\hline Xafis et al. [31] & Urinalysis & 341 & $341 / 507(67.3)$ & Unenhanced MDCT \\
\hline Kartal et al. [35] & Urinalysis & 121 & $121 / 176(68.8)$ & IVU, US, spiral CT, stone passage \\
\hline Gaspari and Horst [37] & Urinalysis & 54 & $54 / 58(93.1)$ & US, $\subset$ T \\
\hline Argyropoulos et al. [8] & Urine dipstick & 539 & 539/564 (95.6) & Abdomen X-ray, US \\
\hline Unal et al. [38] & Urinalysis & 92 & $92 / 114(80.7)$ & US, excretory urography, non-enhanced helical CT \\
\hline Tack et al. [39] & $\begin{array}{l}\text { Urinalysis or Urine } \\
\text { dipstick }\end{array}$ & 37 & $37 / 38(97.4)$ & Excretory urography, non-enhanced helical MDCT \\
\hline \multirow[t]{2}{*}{ Kobayashi et al. [40] } & Urine dipstick & 346 & 346/452 (76.5) & Abdomen X-ray, US, CT \\
\hline & Urinalysis & 317 & $317 / 452(70.1)$ & \\
\hline Eray et al. [41] & Urinalysis & 37 & $37 / 54(68.5)$ & Abdomen X-ray, spiral $C T$, stone passage \\
\hline Luchs et al. 42[ & Urinalysis & 492 & 492/587 (83.8) & $C T$, stone passage \\
\hline Hamm et al. [43] & Urinalysis & 53 & $53 / 80(66.3)$ & Unenhanced low dose elical CT \\
\hline Li et al. [44] & $\begin{array}{l}\text { Urinalysis or Urine } \\
\text { dipstick }\end{array}$ & 360 & 360/397 (90.7) & $C T, I V P$ \\
\hline Hamm et al. [45] & Urinalysis & 76 & 76/91 (83.5) & Helical CT \\
\hline $\begin{array}{l}\text { Richards and Christman } \\
{[46]}\end{array}$ & Urinalysis & 88 & 88/98 (89.8) & IVU \\
\hline \multirow[t]{3}{*}{ Bove et al. [47] } & Urine dipstick & 70 & 70/87 (80.5) & $\subset \mathrm{T}$ \\
\hline & Urinalysis & 77 & 77/95 (81.1) & \\
\hline & $\begin{array}{l}\text { Urinalysis or Urine } \\
\text { dipstick }\end{array}$ & 82 & $82 / 95(86.3)$ & \\
\hline \multirow[t]{2}{*}{ Ooi et al. [9] } & Urine dipstick & 62 & $62 / 65(95.4)$ & Abdomen X-ray, IVU \\
\hline & Urinalysis & 46 & $46 / 65(70.8)$ & \\
\hline Ghali et al. [48] & Urinalysis & 64 & $64 / 82(78)$ & Abdomen X-ray, IVU, US \\
\hline Gimondo et al. [50] ${ }^{\mathrm{a}}$ & Urine dipstick & 29 & $29 / 29(100)$ & US \\
\hline Boyd and Gray [51] & Urine dipstick & 29 & $29 / 29(100)$ & Abdomen X-ray, IVU \\
\hline Press and Smith [52] & Urinalysis & 78 & 78/109 (71.6) & IVU \\
\hline Stewart et al. [55] & Urinalysis & 132 & $132 / 160(82.5)$ & IVP \\
\hline Freeland [56] & Urine dipstick & 72 & 72/76 (94.7) & IVU or stone passage \\
\hline Dunn et al. [57] & Urinalysis & 62 & $62 / 76(81.6)$ & IVU or stone passage \\
\hline Bishop [58] & Urine dipstick & 33 & 33/35 (94.3) & IVU \\
\hline
\end{tabular}

Abbreviations (alphabetical order): CT computed tomography, HFU High-power field, IVU Intravenous Urography, MDCT multidetector CT, NR not reported, RBC Red Blood Cell, SD standard deviation, US ultrasound

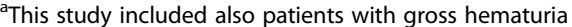




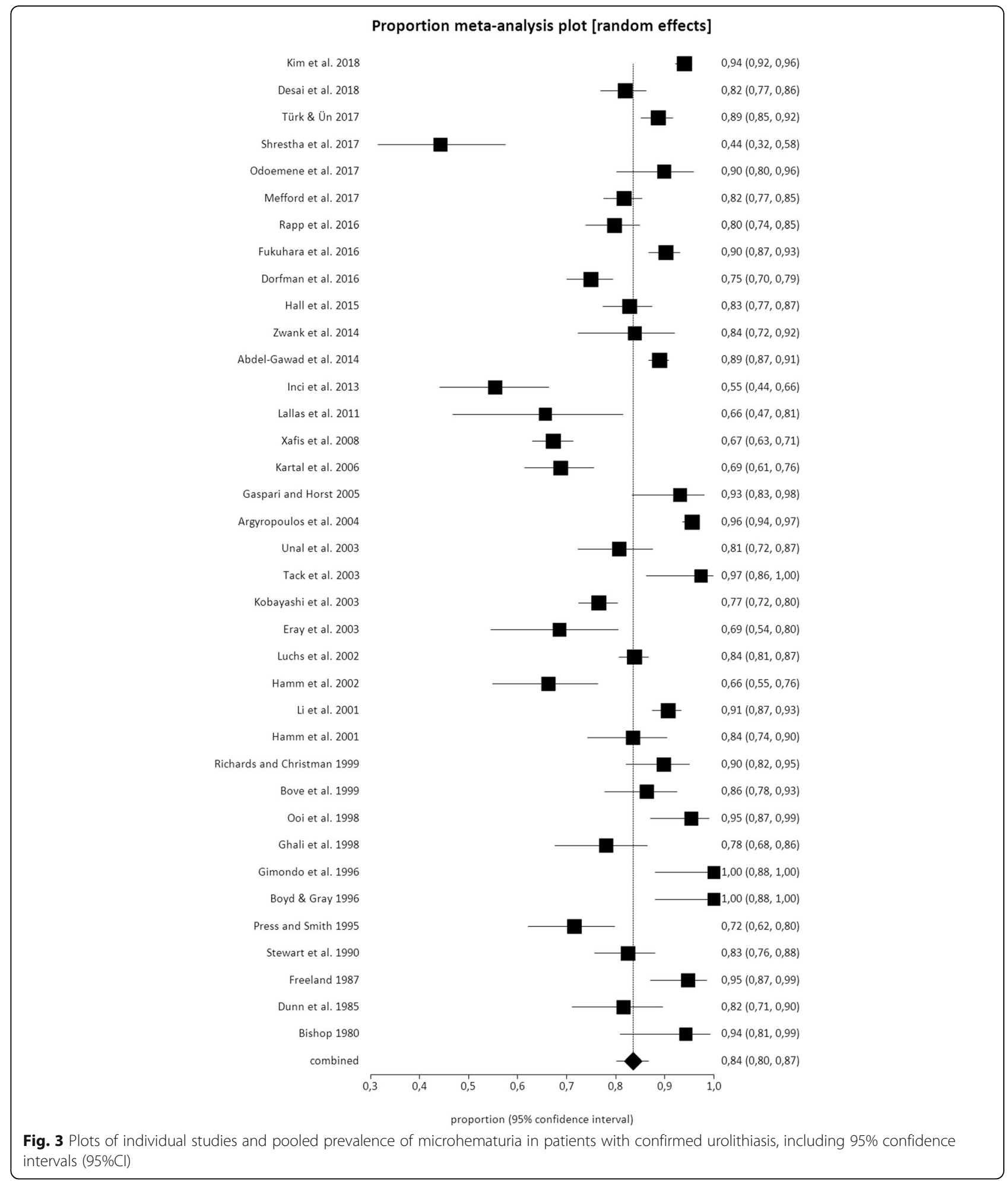

Score with addition of point-of-care ultrasound of the kidney to the original STONE Score. Presence of hydronephrosis improved the specificity up to $98 \%$ and helped to identify patients requiring urological intervention, without remarkably increasing risk stratification.
Considering the moderate sensitivity of microhematuria in patients with renal colic, Xafis et al. [31] suggested to perform a MDCT without urinalysis as a prerequisite. This approach seems to show the best diagnostic accuracy; however, it would increase the number of MDCT with more 
costs and radiation exposure. Therefore, the focus should be placed in complicated urolithiasis (e.g., obstructive pyelonephritis) or dangerous alternative diagnosis. Rucker et al. [61] reported numerous diseases mimicking urolithiasis. Moore et al. [6] found a lower likelihood of a dangerous alternative diagnosis $(<2 \%)$ by using high STONE scores and suggested for this group the possibility to initially avoid compute tomography because till $90 \%$ of stones $<7 \mathrm{~mm}$ will pass through spontaneously [62]. With the same approach the American College of Emergency Physicians (ACEP) suggests in the Choosing Wisely group to avoid ordering computed tomography of the abdomen and pelvis in young except healthy emergency department patients (age $<50)$ with known histories of kidney stones, or ureterolithiasis, presenting with symptoms consistent with uncomplicated renal colic [63]. In fact, taking all studies together, the prevalence of patients with renal colic having effectively urolithiasis was 66\% (median, IQR 52-76), which means a higher pre-test probability in the studied population and so a good discerning capacity of the treating physicians. Anyway, alternative diagnoses mimicking renal colic have to be taken into account. Commons diagnoses are pyelonephritis, appendicitis, diverticulitis, adnexal cysts/ tumor, cholecystitis, and lumbago/sciatica. Rarer pneumonia, lymphoma or aortic dissection/aneurysm. However CT scan negative rate reach till 31\% [42] and Zwank et al. [27] could show that CT scan didn't change management when providers did not expect it would. Finally, alternative diagnosis mimicking renal colic could be found by ultrasonography at least in one study with the same accuracy as MDCT [64].

Some limitations and biases of our meta-analysis should be taken into account. We have no registered a protocol of the systematic review on a database such as PROSPERO. We included some retrospective studies because of the good data quality. Heterogeneity among studies may represent a potential source of bias in a meta-analysis. This heterogeneity is likely to arise through baseline differences among patients in the included studies (Table 1), or diversity in methodological aspects between different studies (Table 2). Unfortunately, we detected a significant heterogeneity in our meta-analysis. We believe that, beyond the various microhematuria tests (urinalysis vs dipstick), the most important source of heterogeneity could be the different definitions of microhematuria (Table 2). Finally, we found presence of publication bias.

In conclusion, microhematuria searched with urine dipstick showed higher diagnostic sensitivity and should be used in this setting as a "gold standard"; it is needed to calculate the STONE score, which can help to identify patients with decreased likelihood of a differential diagnosis, reducing costs and radiation exposure of MDCT. Finally, the concomitant use of ultrasound could increase the specificity till $98 \%$ by hydronephrosis, identify patients requiring urological intervention and help to find alternative diagnosis in each risk group. Especially for searching differential diagnosis with ultrasound in patients with suspected renal colic, further studies should be undertaken. Larger prospective multicenter validation study of the STONE score could provide more definitive evidence.

\section{Supplementary information}

Supplementary information accompanies this paper at https://doi.org/10. 1186/s12894-020-00690-7.

Additional file 1 Supplemental figure 1. Overall quality assessment of the studies included in the systematic review according to QUADAS-2 tool.

Additional file 2 Appendix 1. Search strategy used for PubMed/ MEDLINE and Cochrane Central Register of Controlled Trials (CENTRAL).

\section{Abbreviations}

MDCT: multi-detector computed tomography; QUADAS: Quality Assessment of Diagnostic Accuracy Studies; Cl: Confidence interval; PRISMA: Preferred Reporting Items for Systematic Reviews and Meta-Analyses; BUN: Blood urea nitrogen; ACEP: American College of Emergency Physicians; IQR: Interquartile range; $\mathrm{CT}$ : Computed tomography

\section{Acknowledgments}

This work was carried out in collaboration with the Clinical Trial Unit of Ente Ospedaliero Cantonale (Ticino, Switzerland).

\section{Authors' contributions}

Concept: BM, AS. Literature search: MP, GT. Statistical analysis: MP, GT. Data interpretation: MP, GT, BM, AS. Manuscript writing: MP, GT, BM, AS.

Substantial review: SC, LC, LA. Final approval: all authors.

\section{Funding}

None.

Availability of data and materials

Not applicable.

Ethics approval and consent to participate

Not applicable.

Consent for publication

Not applicable.

Competing interests

No competing interests to declare.

Author details

'Emergency Department, Cantonal Hospital of St. Gallen, Rorschacher Strasse 95, CH-9007 St. Gallen, Switzerland. 'Heath Technology Assessment Unit, Ente Ospedaliero Cantonale, Bellinzona, Switzerland. ${ }^{3}$ Clinical Trial Unit, Ente Ospedaliero Cantonale, Bellinzona, Switzerland. ${ }^{4}$ Department of Intensive Care Medicine, Clinica Luganese, Lugano, Switzerland. ${ }^{5}$ Department of Anesthesia, Ospedale San Giovanni, Bellinzona, Switzerland.

Received: 16 October 2019 Accepted: 29 July 2020

Published online: 08 August 2020

\section{References}

1. Bultitude M, Rees J. Management of renal colic. BMJ. 2012;345:e5499.

2. Tasian GE, Ross ME, Song L, Sas DJ, Keren R, Denburg MR, et al. Annual incidence of nephrolithiasis among children and adults in South Carolina from 1997 to 2012. Clin J Am Soc Nephrol. 2016;11:488-96. 
3. Scales CD Jr, Smith AC, Hanley JM, Saigal CS. Prevalence of kidney stones in the United States. Eur Urol. 2012;62:160-5.

4. Curhan G. 47 - nephrolithiasis. In: Gilbert SJ, Weiner DE, editors. National Kidney Foundation primer on kidney diseases. 6th ed. Philadelphia: W.B. Saunders; 2014. p. 405-11.

5. Romero V, Akpinar H, Assimos DG. Kidney stones: a global picture of prevalence, incidence, and associated risk factors. Rev Urol. 2010;12:e86-96.

6. Moore CL, Bomann S, Daniels B, Luty S, Molinaro A, Singh D, et al. Derivation and validation of a clinical prediction rule for uncomplicated ureteral stone--the STONE score: retrospective and prospective observational cohort studies. BMJ. 2014;348:92191.

7. Inci MF, Ozkan F, Bozkurt S, Sucakli MH, Altunoluk B, Okumus M. Correlation of volume, position of stone, and hydronephrosis with microhematuria in patients with solitary urolithiasis. Med Sci Monit. 2013;19:295-9.

8. Argyropoulos A, Farmakis A, Doumas K, Lykourinas M. The presence of microscopic hematuria detected by urine dipstick test in the evaluation of patients with renal colic. Urol Res. 2004;32:294-7.

9. Ooi SB, Kour NW, Mahadev A. Haematuria in the diagnosis of urinary calculi. Ann Acad Med Singap. 1998;27:210-4

10. Moher D, Liberati A, Tetzlaff J, Altman DG. Preferred reporting items for systematic reviews and meta-analyses: the PRISMA statement. PLoS Med 2009;6:e1000097.

11. Higgins JP, Thompson SG. Quantifying heterogeneity in a meta-analysis. Stat Med. 2002;21:1539-58

12. Harbord RM, Egger M, Sterne JA. A modified test for small-study effects in metaanalyses of controlled trials with binary endpoints. Stat Med. 2006;25:3443-57.

13. Kim TH, Oh SH, Park KN, Kim HJ, Youn CS, Kim SH, et al. Factors associated with absent microhematuria in symptomatic urinary stone patients. Am J Emerg Med. 2018;36(12):2187-91.

14. Desai V, Cox M, Deshmukh S, Roth CG. Contrast-enhanced or noncontrast $\mathrm{CT}$ for renal colic: utilizing urinalysis and patient history of urolithiasis to decide. Emerg Radiol. 2018;25:455-60.

15. Turk H, Un S. Predictive factors for stone disease in patients with renal colic. Arch Ital Urol Androl. 2017:89:143-5.

16. Shrestha R, Bista Y, Khan A. Current diagnostic approach and initial treatment patterns for renal colic in emergency department. J Nepal Health Res Counc. 2017;15:38-43.

17. Odoemene CA, Okere P, Ugonabo MC. Ureterolithiasis: management in an environment with limited facilities. Niger J Clin Pract. 2017;20:622-8.

18. Mefford JM, Tungate RM, Amini L, Suh D, Anderson CL, Rudkin SE, et al. A comparison of Urolithiasis in the presence and absence of microscopic hematuria in the emergency department. West J Emerg Med. 2017;18:775-9.

19. Rapp DE, Wood NL, Bassignani M, Gergoudis L, Caulkins S, Kramolowsky EV. Clinical variables and stone detection in patients with flank pain. Can J Urol. 2016;23:8441-5.

20. Park YH, Jung RB, Lee YG, Hong CK, Ahn JH, Shin TY, et al. Does the use of bedside ultrasonography reduce emergency department length of stay for patients with renal colic?: a pilot study. Clin Exp Emerg Med. 2016;3:197-203.

21. Hernandez N, Song Y, Noble VE, Eisner BH. Predicting ureteral stones in emergency department patients with flank pain: an external validation of the STONE score. World J Urol. 2016:34:1443-6.

22. Fukuhara H, Ichiyanagi O, Kakizaki H, Naito S, Tsuchiya N. Clinical relevance of seasonal changes in the prevalence of ureterolithiasis in the diagnosis of renal colic. Urolithiasis. 2016;44:529-37.

23. Dorfman M, Chan SB, Hayek K, Hill C. Pyuria and urine cultures in patients with acute renal colic. J Emerg Med. 2016;51:358-64.

24. Yan JW, McLeod SL, Edmonds ML, Sedran RJ, Theakston KD. Risk factors associated with urologic intervention in emergency department patients with suspected renal colic. J Emerg Med. 2015:49:130-5.

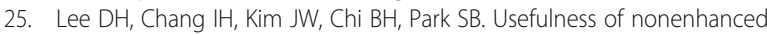
computed tomography for diagnosing Urolithiasis without Pyuria in the emergency department. Biomed Res Int. 2015;2015:810971.

26. Hall TC, Stephenson JA, Rangaraj A, Mulcahy K, Rajesh A. Imaging protocol for suspected ureteric calculi in patients presenting to the emergency department. Clin Radiol. 2015;70:243-7.

27. Zwank MD, Ho BM, Gresback D, Stuck LH, Salzman JG, Woster WR. Does computed tomographic scan affect diagnosis and management of patients with suspected renal colic? Am J Emerg Med. 2014;32:367-70.

28. Abdel-Gawad M, Kadasne R, Anjikar C, Elsobky E. Value of color Doppler ultrasound, kub and urinalysis in diagnosis of renal colic due to ureteral stones. Int Braz j Urol. 2014;40:513-9.
29. Lallas CD, Liu XS, Chiura AN, Das AK, Bagley DH. Urolithiasis location and size and the association with microhematuria and stone-related symptoms. J Endourol. 2011;25:1909-13.

30. Perez JA, Palmes Mde L, Ferrer JF, Urdangarain OO, Nunez AB. Renal colic at emergency departments. Epidemiologic, diagnostic and etiopathogenic study. Arch Esp Urol. 2010;63:173-87.

31. Xafis K, Thalmann G, Benneker LM, Stoupis C, Buggy DJ, Zimmermann H, et al. Forget the blood, not the stone! Microhaematuria in acute urolithiasis and the role of early CT scanning. Emer Med J. 2008;25:640-4.

32. Serinken M, Karcioglu O, Turkcuer I, Ozkan HI, Keysan MK, Bukiran A. Analysis of clinical and demographic characteristics of patients presenting with renal colic in the emergency department. BMC Res Notes. 2008;1:79.

33. Cupisti A, Pasquali E, Lusso S, Carlino F, Orsitto E, Melandri R. Renal colic in Pisa emergency department: epidemiology, diagnostics and treatment patterns. Intern Emerg Med. 2008:3:241-4.

34. Matani YS, Al-Ghazo MA. Role of helical nonenhanced computed tomography in the evaluation of acute flank pain. Asian J Surg. 2007;30:45-51.

35. Kartal M, Eray O, Erdogru T, Yilmaz S. Prospective validation of a current algorithm including bedside US performed by emergency physicians for patients with acute flank pain suspected for renal colic. Emerg Med J. 2006; 23:341-4.

36. Kirpalani A, Khalili K, Lee S, Haider MA. Renal colic: comparison of use and outcomes of unenhanced helical CT for emergency investigation in 1998 and 2002. Radiology. 2005;236:554-8.

37. Gaspari RJ, Horst K. Emergency ultrasound and urinalysis in the evaluation of flank pain. Acad Emerg Med Off J Soc Acad Emerg Med. 2005;12:1180-4.

38. Unal D, Yeni E, Karaoglanoglu M, Verit A, OF K. Can conventional examinations contribute to the diagnostic power of unenhanced helical computed tomography in urolithiasis? Urol Int. 2003;70:31-5.

39. Tack D, Sourtzis S, Delpierre I, de Maertelaer V, Gevenois PA. Low-dose unenhanced multidetector $C T$ of patients with suspected renal colic. AJR Am J Roentgenol. 2003;180:305-11.

40. Kobayashi T, Nishizawa K, Mitsumori K, Ogura K. Impact of date of onset on the absence of hematuria in patients with acute renal colic. J Urol. 2003;170: 1093-6.

41. Eray O, Cubuk MS, Oktay C, Yilmaz S, Cete Y, Ersoy FF. The efficacy of urinalysis, plain films, and spiral CT in ED patients with suspected renal colic Am J Emerg Med. 2003;21:152-4.

42. Luchs JS, Katz DS, Lane MJ, Mellinger BC, Lumerman JH, Stillman CA, et al. Utility of hematuria testing in patients with suspected renal colic: correlation with unenhanced helical CT results. Urology. 2002;59:839-42.

43. Hamm M, Knopfle E, Wartenberg S, Wawroschek F, Weckermann D, Harzmann R. Low dose unenhanced helical computerized tomography for the evaluation of acute flank pain. J Urol. 2002;167:1687-91.

44. Li J, Kennedy D, Levine M, Kumar A, Mullen J. Absent hematuria and expensive computerized tomography: case characteristics of emergency urolithiasis. J Urol. 2001;165:782-4.

45. Hamm M, Wawroschek F, Weckermann D, Knopfle E, Hackel T, Hauser H, et al. Unenhanced helical computed tomography in the evaluation of acute flank pain. Eur Urol. 2001;39:460-5.

46. Richards JR, Christman CA. Intravenous urography in the emergency department: when do we need it? Eur J Emerg Med. 1999;6:129-33.

47. Bove P, Kaplan D, Dalrymple N, Rosenfield AT, Verga M, Anderson K, et al. Reexamining the value of hematuria testing in patients with acute flank pain. J Urol. 1999;162:685-7.

48. Ghali AM, Elmalik EM, Ibrahim Al, Abdulhameed E, el Tahir MI. Cost-effective emergency diagnosis plan for urinary stone patients presenting with ureteric colic. Eur Urol. 1998;33:529-37.

49. Eskelinen M, Ikonen J, Lipponen P. Usefulness of history-taking, physical examination and diagnostic scoring in acute renal colic. Eur Urol. 1998;34:467-73.

50. Gimondo P, Mastropasqua G, Cremona A, Mucciaccio C. Early and systematic use of ultrasonography in emergency patients with renal colic: analysis of the actual diagnostic efficacy. Radiol Med. 1996;92:421-4.

51. Boyd R, Gray AJ. Role of the plain radiograph and urinalysis in acute ureteric colic. J Accid Emerg Med. 1996;13:390-1.

52. Press SM, Smith AD. Incidence of negative hematuria in patients with acute urinary lithiasis presenting to the emergency room with flank pain. Urology. 1995:45:753-7.

53. Chia SJ, Lau W, Tan PK, Consigliere D, Li MK, Low CH. Ureteric colic: value of initial investigations and the outcome. Ann Acad Med Singap. 1995;24:366-9. 
54. Elton TJ, Roth CS, Berquist TH, Silverstein MD. A clinical prediction rule for the diagnosis of ureteral calculi in emergency departments. J Gen Intern Med. 1993;8:57-62.

55. Stewart DP, Kowalski R, Wong P, Krome R. Microscopic hematuria and calculus-related ureteral obstruction. J Emer Med. 1990;8:693-5.

56. Freeland P. No haematuria--no IVU. Ir J Med Sci. 1987;156:270-1.

57. Dunn PM, Keller RT, Jones SR. The absence of hematuria in patients with symptomatic urinary tract stones. Western J Med. 1985;142:717-9.

58. Bishop NL. The influence of emergency urography and haematuria on the diagnosis of ureteric colic. Clin Radiol. 1980;31:605-10.

59. Bataille A, Wetzstein M, Hertig A, Vimont S, Rondeau E, Galichon P. Evidence of dipstick superiority over urine microscopy analysis for detection of hematuria. Res Notes. 2016;9:435.

60. Daniels B, Gross CP, Molinaro A, Singh D, Luty S, Jessey R, et al. STONE PLUS: evaluation of emergency department patients with suspected renal colic, using a clinical prediction tool combined with point-of-care limited ultrasonography. Ann Emerg Med. 2016;67:439-48.

61. Rucker CM, Menias CO, Bhalla S. Mimics of renal colic: alternative diagnoses at unenhanced helical CT. Radiographics. 2004;24(Suppl 1):S11-28 discussion S-33.

62. Tao RZ, Qin ZQ, Liu FD, Lv JL. Efficacy and safety of Tamsulosin in the medical expulsion therapy for distal ureteral calculi: a systematic review and meta-analysis of placebo-controlled trials. Urol J. 2019;16:224-31.

63. Ten Things Physicians and Patients Should Question American College of Emergency Physicians 2013-2014.

64. Catalano O, Nunziata A, Sandomenico F, Siani A. Acute flank pain: comparison of unenhanced helical CT and ultrasonography in detecting causes other than ureterolithiasis. Emerg Radiol. 2002;9:146-54.

\section{Publisher's Note}

Springer Nature remains neutral with regard to jurisdictional claims in published maps and institutional affiliations.

Ready to submit your research? Choose BMC and benefit from:

- fast, convenient online submission

- thorough peer review by experienced researchers in your field

- rapid publication on acceptance

- support for research data, including large and complex data types

- gold Open Access which fosters wider collaboration and increased citations

- maximum visibility for your research: over $100 \mathrm{M}$ website views per year

At $\mathrm{BMC}$, research is always in progress.

Learn more biomedcentral.com/submissions 